\title{
Government Reward-Penalty Mechanism in Closed-Loop Supply Chain Based on Dynamics Game Theory
}

\author{
Xiaoqing Zhang $\mathbb{D}^{\mathbb{D}},{ }^{1}$ Yingsheng Su $\mathbb{D},{ }^{1}$ and Xigang Yuan ${ }^{2}$ \\ ${ }^{1}$ Statistics School, Southwestern University of Finances and Economics, Chengdu 611130, China \\ ${ }^{2}$ Business School, Jiangsu Normal University, Xuzhou 221116, China \\ Correspondence should be addressed to Yingsheng Su; suys@swufe.edu.cn
}

Received 10 February 2018; Revised 2 May 2018; Accepted 13 June 2018; Published 11 July 2018

Academic Editor: Seenith Sivasundaram

Copyright (c) 2018 Xiaoqing Zhang et al. This is an open access article distributed under the Creative Commons Attribution License, which permits unrestricted use, distribution, and reproduction in any medium, provided the original work is properly cited.

\begin{abstract}
The paper discusses the government reward-penalty mechanism (RPM) between two competing manufacturers and a recycler in closed-loop supply chain (CLSC) under asymmetric information. According to the dynamics game theory and principal-agent theory, three decision-making models are built: (1) decentralized dynamics game model without RPM, (2) decentralized dynamics game model with carbon emission RPM, and (3) decentralized dynamics game model with carbon emission RPM and recovery ratio RPM. The results show that (1) the carbon emission RPM increases product sale price, while it decreases the WEEE buy-back price and the WEEE recovery ratio, besides the profit of recycler. To some extent, it cannot motivate WEEE recycling. (2) Recovery ratio RPM improves the WEEE recovery ratio and lowers the product sale price; it also benefits manufacturer-1's and recycler's profits and consumers' surplus. So it strongly proved effectiveness in guiding WEEE recycling. (3) In any case, the product sale price of manufacture-1 is lower than that of manufacturer-2. Similarly, the WEEE buy-back price and WEEE recovery ratio with $\mathrm{H}$ type are higher than those of L type, respectively. Apparently, it is suggested that the manufacturer participating in WEEE recycling and remanufacturing can gain competitive advantages; meanwhile, the recycler with high fixed cost has the scale advantages. (4) The competition can benefit improving WEEE recovery ratio. A numerical simulation is given to examine the theoretical results. According to the main conclusions, we propose that taking active part in recycling and remanufacturing WEEE and choosing the recycler with high fixed cost to cooperate are the wise choices for manufacturers. The recycler should expand fixed recovery cost investment, which will contribute to getting the scale effect; the government needs to balance the carbon emission RPM and recovery ratio RPM so as to cut down environmental pollution and guide the CLSC into WEEE recycling and remanufacturing. The most important carbon emission reward-penalty intensity should be set appropriately in case of discouraging members of CLSC recycling WEEE.
\end{abstract}

\section{Introduction}

With the rapid development of the economy and the shortening of the product life cycle, the update speed of the electronic products has been accelerated; at the same time, manufacturers would like to produce more electronic products in order to meet the various needs of customers, so there are more and more waste electrical and electronic equipment (WEEE) in our daily life. According to incomplete statistics, the number of the WEEE all over the world has reached 65 million tonnes by 2017, which increased by about 33\% compared to 49 million tonnes in 2012. On one hand, there are more than seven hundred kinds of chemical components in the WEEE, and most of them are harmful for human body.
On the other hand, the WEEE has great economic value. If so much WEEE cannot be properly handled, this not only causes the waste of recyclable resources but also pollutes environment and endangers people's health. Thus, the WEEE recycling and remanufacturing have gradually attracted extensive concern of countries around the world because of the crisis of the resource shortage and environment pollution.

The closed-loop supply chain (CLSC) is an integration of former supply chain (SC) and reverse supply chain (SC); its efficient operation needs the government's guidance. On one hand, the government makes relevant laws and regulations to restrain the firm's recycling and remanufacturing activity. For example, in Extended Producer Responsibility (EPR) 
law, the government motivates the manufacturers to design environment-friendly products and holds them responsible for collecting and recycling used products; until now, many US states have passed law mandating state wide e-waste recycling. On the other hand, the government takes many incentives to promote firms to recycle the WEEE, including reward and penalty methods. For instance, China put the WEEE Recycling Management Regulation into effect in 2011, which required the manufacturers to pay for the WEEE recycling funds, while subsidizing the recycler for recycling the WEEE. Sometimes we can regard the recycling fund and subsidy as the reward and penalty policy, respectively. Actually, the Chinese government has been playing an important role in the promotion and formation of remanufacturing industry. For example, in China, the government of Liuyang in Hunan province provided a one-time subsidy to motivate enterprises to launch remanufacturing activities that covered $20 \%$ of the total investment of remanufacturing construction and equipment. In Liuyang Remanufacturing Industrial Park in Hunan province in China, remanufacturers can get annual production subsidies ranging from $10000 \mathrm{RMB}$ to $100000 \mathrm{RMB}$ according to their different annual production. Moreover, the government of Wuhan in Hubei province gave Sevalo Construction Machinery Remanufacturing Co. Ltd. 1 million RMB as an R\&D subsidy. All of these policies promote the firm to recycle and remanufacture the WEEE so that it can improve the firm's profit and competitive ability.

Sometimes, recycling and remanufacturing activities do not create enough profit for supply chain (SC) members, although they contribute to environment and society. For example, in China, the electronics industry faces the intense market competition environment and has a very little profit, so it is difficult for the SC members to participate in the recycling and remanufacturing activities. In this case, government as a facilitator can play an effective role to motivate SC members to recycle and remanufacture the WEEE [1].

There is horizontal and vertical competition between members in CLSC. Game theory is often used to research this problem; particularly, the dynamics game theory as a traditional and classical theory reports that the action between the participants is in order; the latter can observe the former's behavior choice, and then the former makes the appropriate choice according to this. Anyway, this game cannot be seen as a simultaneous decision.

Large numbers of scholars discussed the government guidance of recycling and remanufacturing activity. Webster and Mitra [2] established two-stage game model to study the collective versus individual product take-back issue. Moreover, they analyzed the impact of the WEEE recycling law on the interests of manufacturing and remanufacturing activity and proved that the modest recovery ratio and unit recovery cost were good for the manufacturer. Under the remanufacturing competition situation, Mitra and Webster [3] studied the impact of government's remanufacturing subsidy on the manufacturer and the remanufacturer. They pointed out that the government should subsidy both the manufacturer and the remanufacturer. About the case study, Kwok and Wang
[4] researched the China electronics industry reverse supply chain and pointed out that the government subsidy policy was effective to encourage the manufacturer's recovery activity. Mo et al. [5] pointed out that the government could guide the firm to recycle the WEEE with tax incentive policy. Aksen et al. [6] compared the different influence of government policy on the system profit between the government supporting policy and legislative policy and pointed out that the government supporting policy was more advantage to improve the system profit. Atasu and Wassenhove [7] built the government subsidy game model and discussed effective condition for government to legislate the WEEE recycling and remanufacturing policy. Zhu and Dou [8] established three-stage supply chain game model, which considered the product green degree and government subsidy. Fu et al. [9] researched the WEEE disassembly using evolutionary game and found that it was very important for government to guide the WEEE disassembly activity. Xu et al. (2013) built two competitive CLSC decision-making models and gave the optimal government subsidy strategy in terms of benefits maximization of economy and environment. Yu et al. [10] discussed four WEEE recycling decision-making models with government's recycling subsidy policy; lastly they analyzed the impact of different subsidy ways on the recycling activity. Heydari et al. [11] built the game models with and without government intervention and discussed the impact of different government incentives (tax, reward, or subsidy) on the SC coordination.

Most of the above researchers focused on the effectiveness of the government's recycling and remanufacturing subsidy policy, which could be seen as a pure reward policy. Some other scholars recognized tax policy as effective policy in guiding the WEEE recovery activity, which could be thought as a punishment policy. However, some scholars researched the government's recycling and remanufacturing rewardpenalty mechanism (RPM) which combined the reward policy with penalty policy. Under the government rewardpenalty mechanism, Wang and $\mathrm{Da}$ [12] discussed the manufacturer's recycling and remanufacturing decision problem. Moreover, they proved the effectiveness of the reward-penalty mechanism in improving WEEE collection; what is more, this helped to reduce the sale price. Based on the government subsidy policy, Cao et al. [13] combined the subsidy policy with the penalty policy, and they found that the subsidypenalty policy was much more effective. Yi and Liang [14] studied the impact of the reward-penalty mechanism on the hybrid recycling channel decision in CLSC by using dynamics game theory, and the result showed that the hybrid recycling channel including manufacturer and retailer was the most optimal channel in terms of the sale price and the profit. Wang and Deng [15] compared the reward-penalty mechanism with the tax-subsidy mechanism by using the dynamics game theory, and it was shown that the profit and the WEEE recovery ratio were the highest in terms of the reward-penalty mechanism.

The global climate is getting warmer and environmental pollution is getting worse with the development of the economy and society; we should respond to the "low energy consumption and high output" industry so as to build the 
environment-friendly society. From the point of view of the government, the production carbon emission should be constrained to reduce environmental pollution. Thus, it is essential to introduce the carbon emission RPM into the CLSC. Many scholars have done some work about this issue. For instance, based on the carbon emission constraints, Nie et al. [16] researched the price and recovery decision of CLSC by using dynamics game theory, and the result indicated that the relatively large intensity of carbon emission rewardpenalty not only reduced the total quantity and the unit of the carbon emission effectively but also improved the recovery ratio and members' profits of CLSC. Wang et al. [17] studied the reverse supply chain under the manufacturer's competition and discussed the influence of RPM, which combined carbon emission RPM with recovery ratio RPM on the system optimal decisions by using dynamics game theory. The result showed that the recovery ratio RPM increased the WEEE recovery ratio and lowered the sale price.

All the above studies were limited to information symmetry. However, the asymmetric information in SC is a common phenomenon, especially in CLSC. The information asymmetry may reduce supply chain performance. Thus, under asymmetric information, it is very important to research the government RPM for improving CLSC system performance and coordination. Assuming that the retailer's operation cost is asymmetric information, Gong et al. [18] studied reverse supply chain decision problem under different situations: without government intervention, government reward manufacturer, and government RPM by using dynamics game theory and the principal-agent theory. Finally, they proved that the RPM was the optimal situation. Then Gong and Ge [19] made further research about the government leading reverse supply chain under dual asymmetric information. Wang et al. [20] explored the RPM in electronic product reverse supply chain under asymmetric information. They compared the decision with and without the RPM by principal-agent theory and fully demonstrated the effectiveness of the RPM in directing WEEE recycling. Then, Wang et al. [21] examined the RPM in CLSC under asymmetric information again; the result showed that the RPM could reduce the wholesale price and sale price; meanwhile, it also improved the buy-back price and recycling amount. Based on above analysis, some disadvantages existed in the above papers.

First, most researches focus on the effectiveness of the government's recycling and remanufacturing subsidy policy, which can be seen as a pure reward policy. Some scholars recognize tax policy as effective in guiding the WEEE recovery activity, which can be thought of as a punishment policy. However, few scholars researched the government's rewardpenalty mechanism (RPM), which combined reward policy and penalty policy.

Second, some scholars pay attention to the government's guidance (recycling regulation and incentives) on the recycling and remanufacturing in reverse supply chain. Other scholars research the government's carbon emission constraints policy in the forward supply chain considering the global warming and environmental pollution. Only few scholars study the government policy that integrates the forward supply chain and the reverse supply chain, such as the carbon emission reward-penalty mechanism and the recovery ratio reward-penalty mechanism.

Third, some of the above papers discuss the government's policy under the symmetric information; other articles discuss the government's policy under the carbon emission constraint. However, few papers discuss the government's reward-penalty mechanism in closed-loop supply chain under the asymmetric information and dynamics game theory.

Based on the above analysis, the main contribution in this paper is as follows.

First, we research the impact of the government's rewardpenalty mechanism (RPM), which combined reward policy and penalty policy on the WEEE's recycling and remanufacturing activity in closed-loop supply chain.

Second, we research the government policy in closedloop supply chain, which integrates the forward supply chain and the reverse supply chain. Moreover, we discuss the impact of the government's carbon emission reward-penalty mechanism and the recovery ratio reward-penalty mechanism on the WEEE's recycling and remanufacturing activity in closedloop supply chain.

Third, we discuss the government's reward-penalty mechanism in closed-loop supply chain under the asymmetric information. What is more, we build three decision-making models and solve the model by using dynamics game theory and principal-agent theory.

The remainder of this paper is structured as follows. In Section 2, the assumption and notation are presented. In Section 3, three dynamics game theories are analyzed, and the main result is derived. Section 4 gives a numerical simulation to examine the theoretical result and Section 5 gives the conclusion and direction for future research.

\section{Assumptions and Notations}

This paper considers a CLSC with two manufacturers, customer, recycler, and government. Manufacturer-1 recycles the WEEE, while manufacturer-2 does not recycle the WEEE. The relevant assumption, notation, and decision process can be seen as follows:

\subsection{Notations}

$\beta_{j}$ : the recovery difficulty coefficient when the recycler chooses contract $j$, where $j \in\{\mathrm{H}, \mathrm{L}\}$

$\tau_{j}$ : the recovery ratio when the recycler chooses contract $j$, where $j \in\{\mathrm{H}, \mathrm{L}\}$

$I_{j}$ : the recovery fixed cost when the recycler chooses contract $j$, where $j \in\{\mathrm{H}, \mathrm{L}\}$

$c_{d}$ : manufacturer-1's unit sorting cost

$c_{r}$ : manufacturer-one's production cost of using the WEEE material 


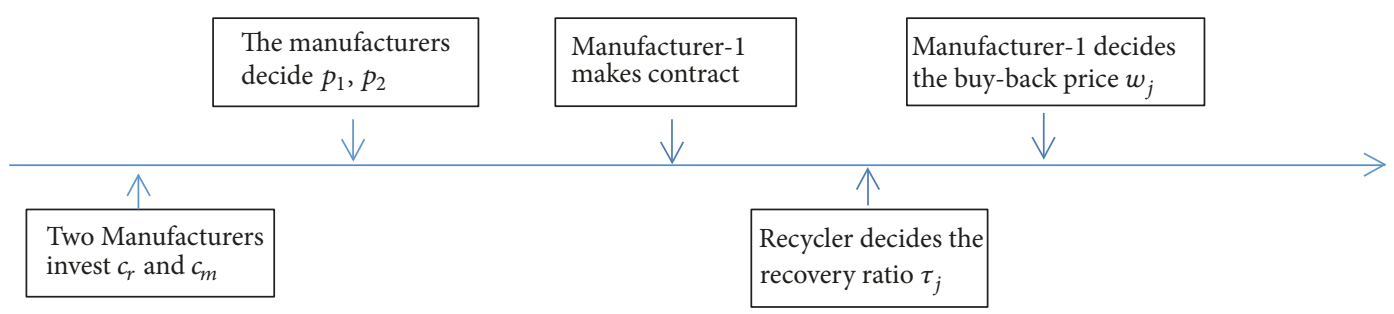

FIgURE 1: Timeline of events.

$c_{m}$ : manufacturers' production cost of using new material

$c$ : unit recovery cost in recycler

$p_{i}$ : unit sale price of manufacturer- $i \quad i=1,2$

$w_{j}$ : WEEE buy-back price of manufacturer-1 when the recycler chooses contract $j$, where $j \in\{\mathrm{H}, \mathrm{L}\}$

$q_{i}$ : the market demand of manufacturer $-i, q_{i}=\alpha-p_{i}+$ $\varepsilon p_{j}$, where $\alpha$ is the potential market demand, $\varepsilon$ is the products substitute coefficient, and $0<\varepsilon<1(j, i=$ $1,2 ; j, \neq i)$

$\tau_{0}$ : the target recovery ratio set by government

$e_{0}$ : the target carbon emission set by government

$f$ : the unit carbon emission reward-penalty intensity established by government

$k$ : the unit recovery ratio reward-penalty intensity set by government

\subsection{Assumption}

(1) The recovery fixed cost of the recycler is $I\left(I=\beta \tau^{2}\right) ; \beta$ is the recovery difficulty coefficient.

(2) The production cost of using new material is $c_{n}$, and production cost of using WEEE material is $c_{r}$. What is more, $c_{r}<c_{n}$. Thus, we assume that manufacturer-1 uses the WEEE material at first and then uses the new material until the WEEE material is used out. To guarantee the economic significance of the model, we have the following equations: $c<w, c_{r}+c_{d}+w<c_{m}$, and $c_{m}-c_{r}-c_{d}=\Delta$.

(3) Two manufacturers act as the channel leaders; the recycler acts as the channel follower.

(4) The remanufacturing ratio in manufacturer-1 is one hundred percent.

(5) The unit carbon emissions in two manufacturers are the same, which can be expressed as $e_{0}$.

(6) We only discuss the role of carbon emission RPM and the role of recovery ratio RPM, respectively, instead of the interactive relationship between the two RPMs.

2.3. Decision Process. The dynamics game model of the CLSC government RPM is assumed to have the following timing (Figure 1).

(1) The manufacturers invest $c_{r}$ and $c_{m}$ to produce new production; these investments are irreversible and common information.
(2) The manufacturers decide the product sale prices $p_{1}$ and $p_{2}$ at the same time, and the recovery fixed cost is the recycler's private information that can be expressed as $I$ ( $I=$ $\beta \tau^{2}$ ), which is invisible for manufacturer-1.

Assume that there are two kinds of recovery fixed cost $(H$ and $L)$.

(3) Manufacturer-1 makes the information screening contract which can be expressed as $\left\{G_{H}\left(\tau_{H}, \mathrm{w}_{H}\right), G_{L}\left(\tau_{L}, \mathrm{w}_{L}\right)\right\}$ to recognize the recycler's recovery fixed cost.

(4) With different dynamics game models considered in step (3), the manufacturers get the product sale prices $p_{1}$ and $p_{2}$; the recycler can decide the recovery ratio $\tau_{j}$.

(5) According to recycler's recovery ratio, manufacturer1 can decide the buy-back price $w_{j}$. Lastly, the information screening contract is executed.

\section{Dynamics Game Model}

This section discusses the application of dynamics game theory in government reward-penalty mechanism in closedloop supply chain. Three dynamics game models are built: (1) decentralized dynamics game model without RPM, (2) decentralized dynamics game model with carbon emission RPM, and (3) decentralized dynamics game model with carbon emission RPM and recovery ratio RPM. The interaction between different node firms in each model is analyzed as a dynamics game (Figure 2).

In Figure 2, there are dynamics game models, of which the dynamics game orders are the same. Thus, we only introduce the dynamics game order in model 1 . The double circles represent the joint-decision node; that is, two manufacturers decide the sale price at the same time. The solid circles represent the individual nodes; that is, the recycler makes the decision of recovery ratio. Note that "G" represents the government, " $\mathrm{M}_{1}$ " represents manufacturer-1, " $\mathrm{M}_{2}$ " represents manufacturer-2, and " $R$ " represents the recycler. The terminal node is labelled with profit vector $\left(\pi_{M_{1}}, \pi_{M_{2}}, \pi_{R}\right)$.

3.1. Model 1: Decentralized Dynamics Game Model without $R P M$. In this model, manufacturers are the channel leaders and the recycler is the channel follower. Manufacturer-1 trusts the recycler to recycle WEEE; the recovery fixed cost belongs to the recycler's private information; manufacturer1 designs the information screening contract to attain the private information of the recycler. The members aim to maximize their profits in decentralized model. The backward 


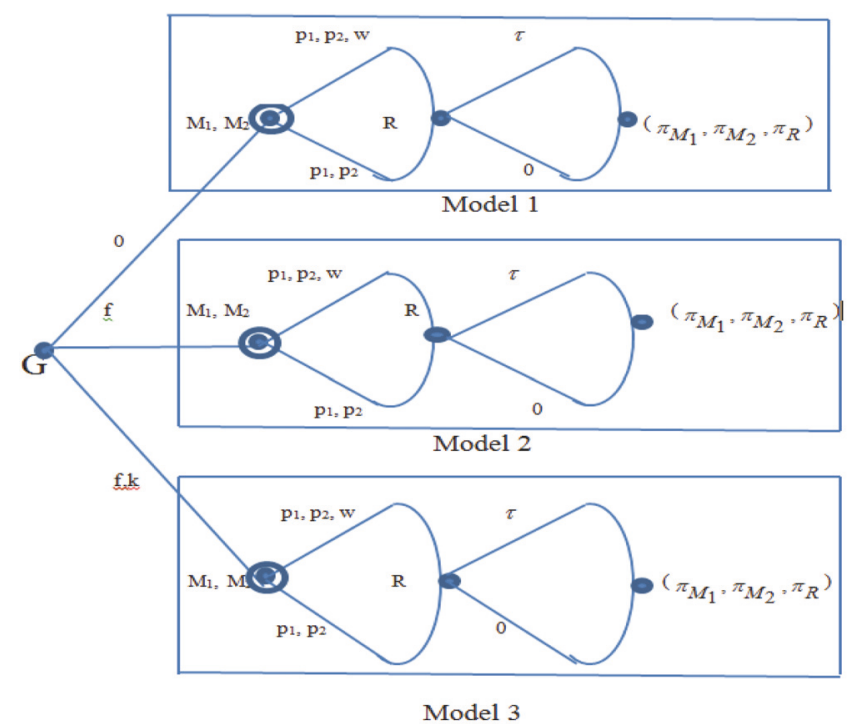

Figure 2: Dynamics game models between different node firms.

induction is applied starting with the recycler's decision. The profit function of the recycler is

$$
\begin{aligned}
\pi_{r}^{(1)} & \\
= & \psi\left\{\left(\alpha-p_{1}+\varepsilon p_{2}\right) \tau_{H}\left(w_{H}-c\right)-\beta_{H}\left(\tau_{H}\right)^{2}\right\} \\
& +(1-\psi)\left\{\left(\alpha-p_{1}+\varepsilon p_{2}\right) \tau_{L}\left(w_{L}-c\right)-\beta_{L}\left(\tau_{L}\right)^{2}\right\}
\end{aligned}
$$

We can get the recycler's recovery ratio $\tau_{H}^{(1)}$ and $\tau_{L}^{(1)}$ :

$$
\begin{aligned}
& \tau_{H}^{(1)}=\frac{\psi\left(2 c_{m}-\Delta+3 c\right)\left(\alpha-p_{1}+p_{2} \varepsilon\right)}{4 \beta_{H}(1-\psi)} \\
& \tau_{L}^{(1)} \\
& =\frac{\left(\beta_{L}(1-\psi)\left(2 c_{m}-\Delta-c\right)+c\left(\beta_{H}-1\right)\right)\left(\alpha-p_{1}+p_{2} \varepsilon\right)}{2 \beta_{L}\left(1+2 \beta_{L}(2-\psi)\right)}
\end{aligned}
$$$$
\pi_{m_{2}}^{(1)}=\left(\alpha-p_{2}+\varepsilon p_{1}\right)\left(p_{2}-c_{m}\right)
$$

$$
p_{1}^{(1)}=\frac{\left\{\left(\beta_{L}(\mathrm{~A})^{2}-\beta_{H}\left(\left(\beta_{L}(1-\psi)(\Delta+c)+c\left(2 \beta_{L}+\beta_{H}\right)\right) /\left(1+2 \beta_{L}(2-\psi)\right)\right)^{2}\right)(\psi-2)-\beta_{L}(\mathrm{~A}-2 c)(\Delta-c)\right\} \mathrm{B}}{(\mathrm{A})\left(2-\varepsilon^{2}\right)\left[\beta_{L}(2 c-\psi \mathrm{A})-\beta_{H}(\psi-2) \mathrm{A}\right]}
$$

$p_{2}^{(1)}$

$$
=\frac{\left(\alpha+c_{m}+\alpha \varepsilon\right)\left\{\beta_{H}(2-\psi)\left[\mathrm{A}^{2} \beta_{L}(\psi-2)\left(\alpha+c_{m}+\alpha \varepsilon\right)+\left(\left(\beta_{L}(1-\psi)(\Delta+c)+2 c \beta_{L}+c \beta_{H}\right) /\left(1+2 \beta_{L}(2-\psi)\right)\right)^{2}\right]-2 \beta_{L} \mathrm{~A}(\mathrm{~A}(\psi-1)-c)\right\}}{(\mathrm{A})\left(2-\varepsilon^{2}\right)\left\{\beta_{L}(2 c-\psi \mathrm{A})-\mathrm{A} \beta_{H}(\psi-2)\right\}}
$$

We define $\mathrm{A}=(\psi(\Delta+c)-2 c) / 2(\psi-1) ; \mathrm{B}=2 \alpha+\alpha \varepsilon+c_{m} \varepsilon$.

$$
w_{L}^{(1)}=\frac{\left(\beta_{L}-\psi \beta_{L}\right)\left(2 c_{m}-\Delta+c\right)+c\left(2 \beta_{L}+\beta_{H}\right)}{\left(1+2 \beta_{L}(2-\psi)\right)}
$$

$$
w_{H}^{(1)}=\frac{\psi\left(2 c_{m}-\Delta+c\right)+2 c}{2(1-\psi)}
$$
bon Emission RPM. Based on model 1, the carbon emission 
RPM is introduced into this case; the total amount of the carbon emission reward-penalty of manufactures can be expressed as $M_{i}=-f\left[q_{i} e_{m}-e_{0}\right](i=1,2)$. The backward induction is applied starting with the recycler's decision. The profit function of the recycler is

$$
\begin{aligned}
= & \psi\left\{\left(\alpha-p_{1}+\varepsilon p_{2}\right) \tau_{H}\left(w_{H}-c\right)-\beta_{H}\left(\tau_{H}\right)^{2}\right\} \\
& +(1-\psi)\left\{\left(\alpha-p_{1}+\varepsilon p_{2}\right) \tau_{L}\left(w_{L}-c\right)-\beta_{L}\left(\tau_{L}\right)^{2}\right\}
\end{aligned}
$$

$\pi_{r}^{(2)}$

We can get the recycler's recovery ratio $\tau_{H}^{(2)}$ and $\tau_{L}^{(2)}$ :

$$
\begin{aligned}
\tau_{H}^{(2)} & =\frac{\left(w_{H}^{(2)}(2-\psi+2 c)-\psi\left(2 c_{m}-\Delta\right)\right)\left(\alpha-p_{1}+p_{2} \varepsilon\right)}{2 \beta_{H}} \\
\tau_{L}^{(2)} & =\frac{\left(\left(w_{L}^{(2)}-c\right)\left(\alpha-p_{1}+p_{2} \varepsilon\right)+(1-\psi)\left(w_{L}^{(2)}+\left(2 c_{m}-\Delta\right)\right)\left(\alpha-p_{2}+p_{1} \varepsilon\right)\right)}{2 \beta_{L}}
\end{aligned}
$$

Then, two manufacturers can make decision based on recycler's decision; the profit functions of manufacturer-1 and manufacturer-2 are

$$
\begin{aligned}
\pi_{m_{1}}^{(2)} & =\psi\left\{\left(\alpha-p_{1}+\varepsilon p_{2}\right)\right. \\
\cdot & \left.\left(p_{1}+\tau_{H}\left(\Delta-w_{H}\right)-c_{m}-f e_{m}\right)+f e_{0}\right\}+(1-\psi) \\
& \cdot\left\{\left(\alpha-p_{2}+\varepsilon p_{1}\right)\left(p_{1}+\tau_{L}\left(\Delta-w_{L}\right)-c_{m}-f e_{m}\right)\right. \\
& \left.+f e_{0}\right\} \\
\pi_{m_{2}}^{(2)} & =\left(\alpha-p_{2}+\varepsilon p_{1}\right)\left(p_{2}-c_{m}-f e_{m}\right)+f e_{0}
\end{aligned}
$$

We can get product sale prices $p_{1}^{(2)} p_{2}^{(2)}$ and the buy-back price $w_{H}^{(2)} w_{L}^{(2)}$.

$$
\begin{aligned}
p_{1}^{(2)} & =p_{1}^{(1)} \\
+ & \frac{2 f e_{m}(\Delta+c)}{\mathrm{A}\left(2-\varepsilon^{2}\right)\left[\mathrm{A}\left(\beta_{L}-\beta_{H}\right)(\psi-2)-\beta_{L}(\psi(\Delta+c)-4 c)\right]} \\
p_{2}^{(2)} & =p_{2}^{(1)} \\
+ & \frac{2 f(\Delta+c)}{\mathrm{A}\left(2-\varepsilon^{2}\right)\left[\mathrm{A}\left(\beta_{L}-\beta_{H}\right)(\psi-2)-\beta_{L}(\psi(\Delta+c)-4 c)\right]}
\end{aligned}
$$

The same as the above, $\mathrm{A}=(\psi(\Delta+c)-2 c) / 2(\psi-1) ; \mathrm{B}=$ $2 \alpha+\alpha \varepsilon+c_{m} \varepsilon$.

$$
\begin{aligned}
& w_{H}^{(2)}=\frac{\psi\left(2 c_{m}-\Delta+c\right)+2 c-3 f(\Delta+c) e_{m}-f \Delta}{2(1-\psi)}=w_{H}^{(1)}-\frac{3 f(\Delta+c) e_{m}+f \Delta}{2(1-\psi)} \\
& w_{L}^{(2)}=\frac{\left(\beta_{L}-\psi \beta_{L}\right)\left(2 c_{m}-\Delta+c\right)+2 c\left(2 \beta_{L}+\beta_{H}\right)-4 f(\Delta+c) e_{m}-f \Delta}{\left(1+2 \beta_{L}(2-\psi)\right)}=w_{L}^{(1)}-\frac{4 f(\Delta+c) e_{m}+f \Delta}{\left(1+2 \beta_{L}(2-\psi)\right)}
\end{aligned}
$$

3.3. Model 3: Decentralized Dynamics Game Model with Carbon Emission RPM and Recovery Ratio RPM. In this model, the government imposes the carbon emission RPM and the recovery ratio RPM on CLSC. The total amount of the carbon emission reward-penalty of manufactures is the same as model 2. And the total amount of the recovery ratio reward-penalty for manufacturer-1 can be marked as $k(\tau-$ $\left.\tau_{0}\right)$; the total amount of the recovery ratio reward-penalty for manufacturer-2 is $\left(-k \tau_{0}\right)$ because it does not recycle the
WEEE. The backward induction is applied starting with the recycler's decision. The profit function of the recycler is

$$
\begin{aligned}
& \pi_{r}^{(3)} \\
& =\psi\left\{\left(\alpha-p_{1}+\varepsilon p_{2}\right) \tau_{H}\left(w_{H}-c\right)-\beta_{H}\left(\tau_{H}\right)^{2}\right\} \\
& \quad+(1-\psi)\left\{\left(\alpha-p_{1}+\varepsilon p_{2}\right) \tau_{L}\left(w_{L}-c\right)-\beta_{L}\left(\tau_{L}\right)^{2}\right\}
\end{aligned}
$$

We can get the recycler's recovery ratio $\tau_{H}^{(3)}$ and $\tau_{L}^{(3)}$ :

$$
\begin{aligned}
\tau_{H}^{(3)} & =\frac{\left(w_{H}^{(3)}(2-\psi-2 c)-\psi\left(2 c_{m}-\Delta\right)\right)\left(a-p_{1}+p_{2} \varepsilon\right)+w_{H}^{(3)} k(\Delta+c) \tau_{0}}{2 \beta_{H}} \\
\tau_{L}^{(3)} & =\frac{\left(\left(w_{L}^{(3)}-c\right)\left(\alpha-p_{1}+p_{2} \varepsilon\right)+\left(2(\Delta+3 c)+\tau_{0}\right) k+(1-\psi)\left(w_{L}^{(3)}+\left(2 c_{m}-\Delta\right)\right)\left(\alpha-p_{2}+p_{1} \varepsilon\right)\right)}{2 \beta_{L}}
\end{aligned}
$$




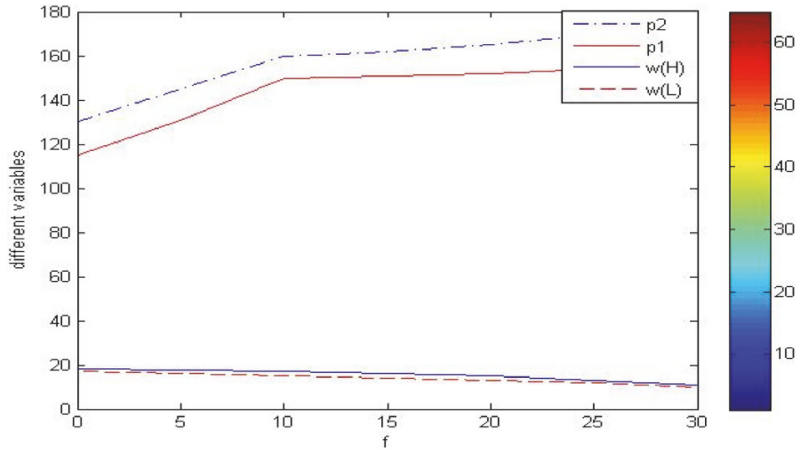

FIGURE 3: The impact of carbon emission reward-penalty intensity $f$ on the variation of different variables between model 1 and model 2 .

Then, two manufacturers can make decision based on recycler's decision; the profit functions of manufacturer-1 and manufacturer- 2 are

$$
\begin{aligned}
& \pi_{m_{1}}^{(3)}=\psi\left\{\left(\alpha-p_{1}+\varepsilon p_{2}\right)\right. \\
& \quad \cdot\left(p_{1}+\tau_{H}\left(\Delta-w_{H}\right)-c_{m}-f e_{m}\right)+f e_{0} \\
& \left.\quad+k\left(\tau_{H}-\tau_{0}\right)\right\}+(1-\psi)\left\{\left(\alpha-p_{1}+\varepsilon p_{2}\right)\right. \\
& \quad \cdot\left(p_{1}+\tau_{L}\left(\Delta-w_{L}\right)-c_{m}-f e_{m}\right)+f e_{0} \\
& \left.\quad+k\left(\tau_{L}-\tau_{0}\right)\right\} \\
& \pi_{m_{2}}^{(3)}=\left(\alpha-p_{2}+\varepsilon p_{1}\right)\left(p_{2}-c_{m}-f e_{m}\right)+f e_{0}-k \tau_{0}
\end{aligned}
$$

We can get product sale prices $p_{1}^{(3)} p_{2}^{(3)}$ and the buy-back price $w_{H}^{(3)} w_{L}^{(3)}$.

$$
\begin{aligned}
p_{1}^{(3)} & =p_{1}^{(2)} \\
- & \frac{2(\Delta+c) \mathrm{k}}{\mathrm{A}\left(2-\varepsilon^{2}\right)\left[\mathrm{A}\left(\beta_{L}-\beta_{H}\right)(\psi-2)-\beta_{L}(\psi(\Delta+c)-4 c)\right]} \\
p_{2}^{(3)} & =p_{2}^{(2)} \\
& -\frac{2 c \Delta}{\mathrm{A}\left(2-\varepsilon^{2}\right)\left[\mathrm{A}\left(\beta_{L}-\beta_{H}\right)(\psi-2)-\beta_{L}(\psi(\Delta+c)-4 c)\right]} \\
w_{H}^{(3)} & =w_{H}^{(2)} \\
+ & \frac{(1-\psi)\left(2 c+2 c_{m}+c_{r}\right)+k\left(2 c_{m}-\Delta+c\right)+k \tau_{0} \Delta}{2(1-\psi)} \\
w_{L}^{(3)} & =w_{L}^{(2)}+\frac{\psi \beta_{H}\left(c_{m}+c_{d}+c\right)+2 k(\Delta+c) \tau_{0}}{\left(1+4 \beta_{L}-2 \psi \beta_{L}\right)}
\end{aligned}
$$

\section{Numerical Simulation}

Numerical simulations are given in this part to validate the dynamics game models and develop managerial insights.

In Figure 3, we can find that the products' sale prices $p_{1}$ and $p_{2}$ with carbon emission RPM are higher than the scenarios without RPM, which increase with the RP intensity

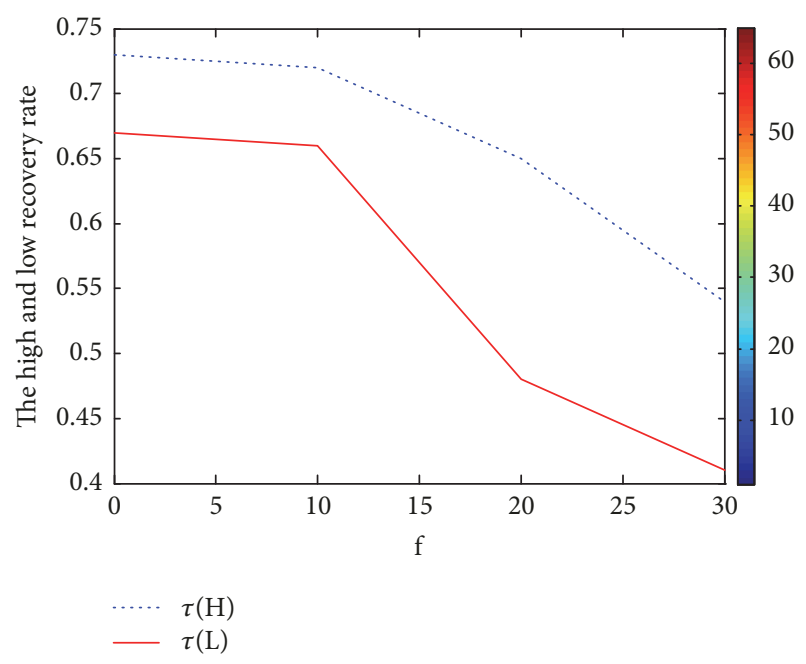

FIGURE 4: The impact of carbon emission reward-penalty intensity $f$ on the recovery ratio between model 1 and model 2 .

$f$. What is more, the sale price of manufacturer- 1 is always lower than the sale price of manufacturer-2. On the contrary, the buy-back prices with carbon emission RPM are lower than the scenarios without RPM, which decrease with the RP intensity $f$. The recycler with high fixed cost can get a higher buy-back price than that of the recycler with low fixed cost. The above means that carbon emission RPM improves products' sale prices and reduces the buy-back price. But the manufacturer involved in WEEE recycling and recycler with high fixed cost have competitive advantage.

Corresponding to the buy-back price in Figure 3, Figure 4 shows that the WEEE recovery ratios with carbon emission RPM are lower than the scenarios without RPM, which decrease with the reward-penalty intensity $f$. The recovery ratio with high fixed cost is higher than that of low fixed cost; what is more, the difference between them increases with increasing carbon emission reward-penalty intensity $f$. This means that carbon emission RPM lowers the WEEE recovery ratio, which is due to increasing products' sale price (reduction in the products demand) and the reduced WEEE buy-back price.

Figure 5 shows that the manufacturer's profit decreases rapidly firstly and then increases rapidly with increasing carbon emission reward-penalty intensity $f$. Since the products' selling prices $p_{1}$ and $p_{2}$ always increase with the increase of carbon emission reward-penalty intensity $f$, the products' demand decreases greatly because of increasing products' selling price when $f<10$ that the manufacturers' profit decreases greatly too; however, the products' selling prices are very high as $f>10$, which compensate for the slow reduction in demand, resulting in the manufacturers' profits increase.

In Figure 6, we can find the changing of products' sale prices $p_{1}$ and $p_{2}$ with both carbon emission RPM and recovery ratio $\mathrm{RPM}$. Given the recovery ratio reward-penalty intensity $k, p_{1}$ and $p_{2}$ increase with the increase of carbon emission reward-penalty intensity $f$, while given the carbon emission reward-penalty intensity $f, p_{1}$ and $p_{2}$ will decrease 


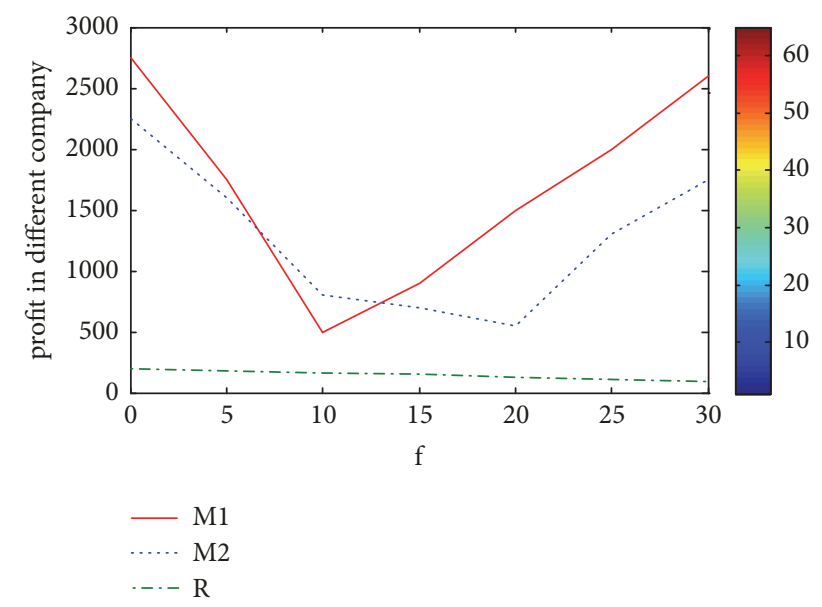

FIGURE 5: The impact of carbon emission reward-penalty intensity $f$ on the profit between model 1 and model 2 .

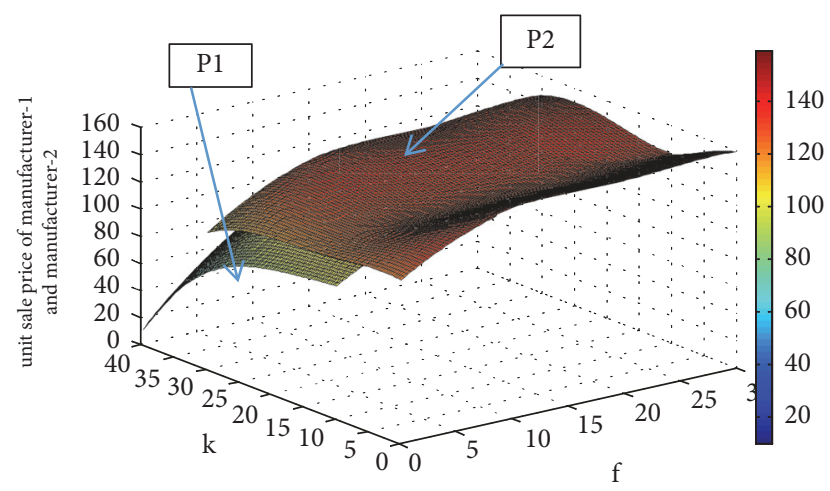

FIGURE 6: The impact of reward-penalty intensity $f$ and $k$ on the sale price.

when the recovery ratio reward-penalty intensity $k$ rises, but, anyway, $p_{1}$ is always less than $p_{2}$. This implies the advantage of recovery ratio RPM in decreasing products' sale price, and manufacturer-1 always has a competitive advantage no matter how the reward-penalty intensity changes.

Figure 7 shows the changing of recovery ratio with both carbon emission RPM and recovery ratio RPM. Contrary to Figure 6, the WEEE recovery ratio decreases with the increase of carbon emission reward-penalty intensity $f$ when the recovery ratio reward-penalty intensity $k$ is given, while given the carbon emission reward-penalty intensity $f$, the WEEE recovery ratio increases with the increasing recovery ratio reward-penalty intensity $k$. Similar to the case with carbon emission RPM, the recovery ratio with high fixed cost is higher than that of low fixed cost. This strongly proves the effectiveness of recovery ratio RPM in improving WEEE collection.

In Figure 8, we can find that the profits of manufacturer1 and recycler increase with the increase of recovery ratio reward-penalty intensity $k$; however, the profit of manufacturer-2 drops. It implies the advantage of recovery ratio RPM in incentivizing manufacturer-1 and recycler to recycle WEEE.

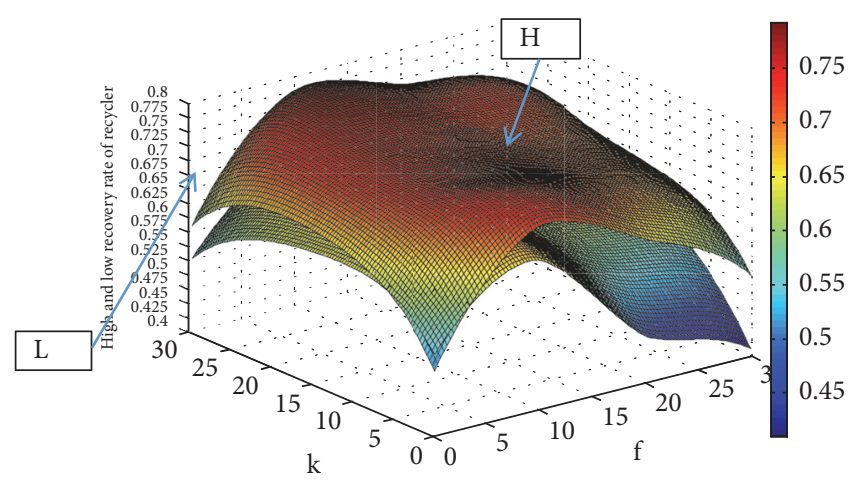

FIgURE 7: The impact of reward-penalty intensity $f$ and $k$ on the recovery ratio.

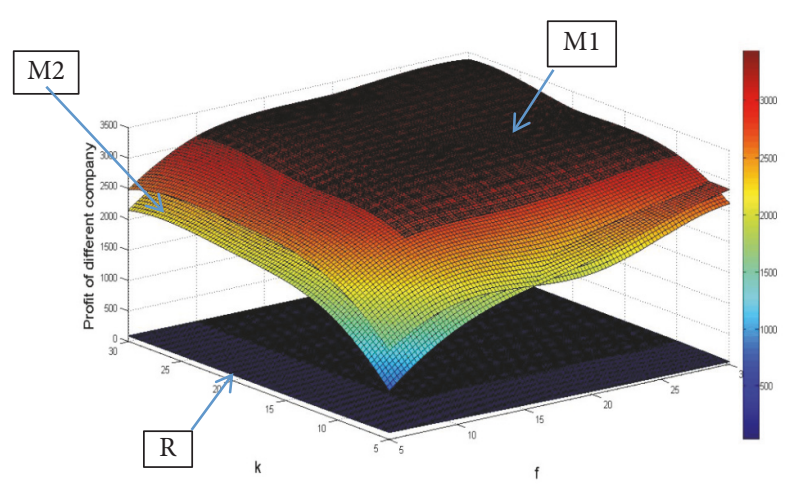

FIGURE 8: The impact of reward-penalty intensity $f$ and $k$ on the profit of different firms.

\section{Conclusions}

In this paper, the application of dynamics game theory in closed-loop supply chain government reward-penalty mechanism is discussed. Three dynamics game models are built with the dynamics game theory and incentive contract theory. In this section, we summarize key findings and develop several managerial suggestions:

(1) The carbon emission reward-penalty mechanism increases product sale price, while it decreases the WEEE buy-back price and WEEE recovery ratio; it also reduces the profit of recycler. To some extent, the carbon emission reward-penalty mechanism is not good for guiding WEEE recycling activity.

(2) Recovery ratio reward-penalty mechanism can improve WEEE recovery ratio and decrease the product sale price; it also improves the profit of manufacture- 1 and the recycler. The conclusion strongly proves that the recovery ratio reward-penalty mechanism can increase the WEEE recovery ratio and improve the consumer's utility.

(3) In any case, manufacturer-1's sale price is always lower than that of manufacturer-2. Generally, manufacturerl's profit is higher than manufacturer-2's profit. This suggests that the manufacturer that participates in WEEE recycling activity can gain competitive advantage; meanwhile, it also attracts manufacturer-2 to participate in WEEE recycling activity. 
(4) No matter what situation, the WEEE buy-back price and WEEE recovery ratio with high fixed cost are always higher than those of low fixed cost, respectively, which shows that high fixed cost recycler has the scale advantages.

(5) The more competition between the manufacturers, the higher the WEEE recovery ratio. It can be said that competition can benefit improving WEEE recovery ratio.

In order to realize the coordination development of the economy, environment, and society in closed-loop supply chain, based on above conclusion, we can get the following managerial insights: (1) From the manufacturers' viewpoint, the manufacturer should improve the production technology in order to reduce the unit carbon emission. At the same time, they should implement the extended production responsibility and take an active part in recycling and remanufacturing WEEE to gain competitive advantage. They also should choose to cooperate with recycler under high fixed cost condition. (2) For the recycler, it should expand investment of fixed cost and enlarge recovery scale, which contributes to getting the scale effect and reducing recovery difficulty. (3) From the perspective of government, on one hand, the government should take on guiding the reverse supply chain WEEE recycling activity and take some incentives including reward and penalty (subsidies and taxes) to encourage the manufacturer and recycler to participate in the WEEE recovery activity; on the other hand, the government should constrain manufacturers' carbon emission for reducing environmental pollution, such as implementing the carbon emission reward-penalty mechanism. The most important carbon emission reward-penalty intensity set by the government must be appropriate and should avoid increasing product sale price and decreasing WEEE buy-back price resulting from very high carbon emission reward-penalty intensity, which reduces the member's motivation to recycle WEEE in closedloop supply chain.

In this paper, we research the application of dynamics game theory in closed-loop supply chain government rewardpenalty mechanism. However, the article does not discuss the reward-penalty mechanism under the double asymmetric information between the manufacturer and the recycler. This is our future research. In addition, we discuss the rewardpenalty mechanism in closed-loop supply chain under the double asymmetric information and competition in the presence of recycler.

\section{Data Availability}

The data used to support the findings of this study are available from the corresponding author upon request.

\section{Conflicts of Interest}

The authors declare that they have no conflicts of interest.

\section{Acknowledgments}

This work was supported by the Ministry of Education, Humanities and Social Science Planning Funds (no.
16YJC630026 and no. 14YJC630020), the National Natural Science Foundation of China (no. 71501161 and no. 71502037), and the Project of China Scholarship Council (no. 201706980022).

\section{References}

[1] L. Xie and J. Ma, "Study the complexity and control of the recycling-supply chain of China's color TVs market based on the government subsidy," Communications in Nonlinear Science and Numerical Simulation, vol. 38, no. 2, pp. 102-116, 2016.

[2] S. Webster and S. Mitra, "Competitive strategy in remanufacturing and the impact of take-back laws," Journal of Operations Management, vol. 25, no. 6, pp. 1123-1140, 2007.

[3] S. Mitra and S. Webster, "Competition in remanufacturing and the effects of government subsidies," International Journal of Production Economics, vol. 111, no. 2, pp. 287-298, 2008.

[4] K. H. Lau and Y. Wang, "Reverse logistics in the electronic industry of China: A case study," Supply Chain Management Review, vol. 14, no. 6, pp. 447-465, 2009.

[5] H. Mo, Z. Wen, and J. Chen, "China's recyclable resources recycling system and policy: A case study in Suzhou," Resources, Conservation \& Recycling, vol. 53, no. 7, pp. 409-419, 2009.

[6] D. Aksen, N. Aras, and A. G. Karaarslan, "Design and analysis of government subsidized collection systems for incentivedependent returns," International Journal of Production Economics, vol. 119, no. 2, pp. 308-327, 2009.

[7] A. Atasu and S. M. Wassenhove, "Efficient take-back legislation," Production and Operational Management, vol. 18, no. 3, pp. 243-258, 2009.

[8] Q. H. Zhu and D. J. Dou, "Green supply chain management game model under government subsidy," Journal of Management science, vol. 14, no. 6, pp. 86-95, 2011.

[9] X. Y. Fu, Q. H. Zhu, and Y. J. Dou, "The evolution game model of processors choose apart under government control," China's Population, Resources and Environment, vol. 22, no. 1, pp. 70-76, 2012.

[10] F. M. Yu, Y. G. Zhong, and Z. Z. Shen, "Research on WEEE recycling decision-making model considering the government guidance," Journal of Chinese Management Science, vol. 35, no. 5, pp. 131-137, 2014.

[11] J. Heydari, K. Govindan, and A. Jafari, "Reverse and closed loop supply chain coordination by considering government role," Transportation Research Part D: Transport and Environment, vol. 52, pp. 379-398, 2017.

[12] W. B. Wang and Q. L. Da, "Recycling and Remanufacturing decision-making model of the electronic production manufacturer under reward-penalty mechanism," Journal of Chinese Management Science, vol. 30, no. 5, pp. 57-63, 2008.

[13] H.-J. Cao, N. Sha, and Y.-Y. Wang, "Reverse supply chain's incentive analysis under government supervision," in Proceedings of the 2010 2nd International Conference on Industrial Mechatronics and Automation, ICIMA '10, pp. 606-609, China, May 2010.

[14] Y. Y. Yi and J. M. Liang, "Hybrid recovery model in closed-loop supply chain under reward-penalty mechanism," Computer Integrated Manufacturing System, vol. 36, no. 1, pp. 215-223, 2014.

[15] W. B. Wang and W. W. Deng, "Comparing government rewardpenalty mechanism with government subsidy mechanism in 
reverse supply chain," Journal of Chinese Management Science, vol. 36, no. 4, pp. 102-110, 2016.

[16] J. J. Nie, T. Wang, Y. X. Zhao, and L. N. Zhang, "Remanufacturing closed-loop supply chain recovery strategy under carbon emission constraints," Journal of Management in Engineering, vol. 31, no. 3, pp. 249-256, 2015.

[17] W. B. Wang, X. J. Zhao, Z. H. Lu, and M. B. Cheng, "Incentive mechanism in closed-loop supply chain under asymmetric information," Journal of Chinese Management Science, vol. 38, no. 10, pp. 69-77, 2016.

[18] W. W. Gong, H. Li, and C. C. Ge, "The reverse supply chain contract design under asymmetric information," Industrial Engineering and Management, vol. 28, no. 5, pp. 27-32, 2011.

[19] W. W. Gong and C. C. Ge, "The government guide of reverse supply chain coordination under double incomplete information," Industrial Engineering and Management, vol. 29, no. 4, pp. $1-7,2012$.

[20] W. B. Wang, X. D. Chen, M. Zhou, and R. Nie, "Rewardpenalty mechanism in reverse supply chain under asymmetric information," Journal of China Mining University, vol. 39, no. 1, pp. 175-182, 2014.

[21] W. Wang, Y. Zhang, Y. Li, X. Zhao, and M. Cheng, "Closedloop supply chains under reward-penalty mechanism: Retailer collection and asymmetric information," Journal of Cleaner Production, vol. 142, pp. 3938-3955, 2017. 


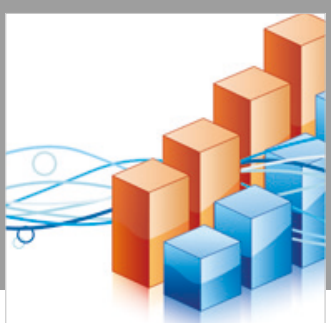

Advances in

Operations Research

\section{-n-m}
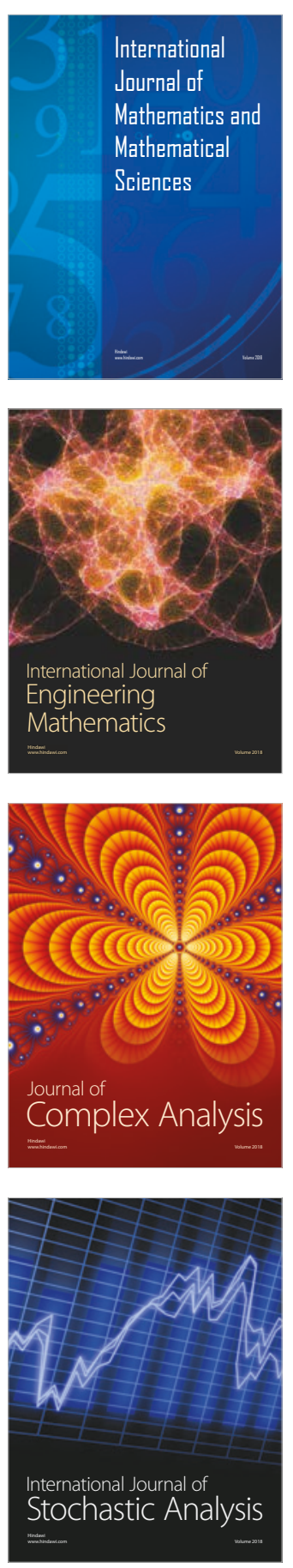
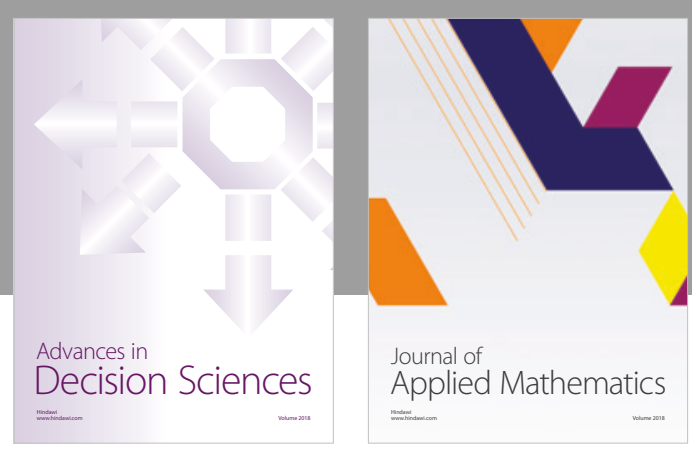

Journal of

Applied Mathematics
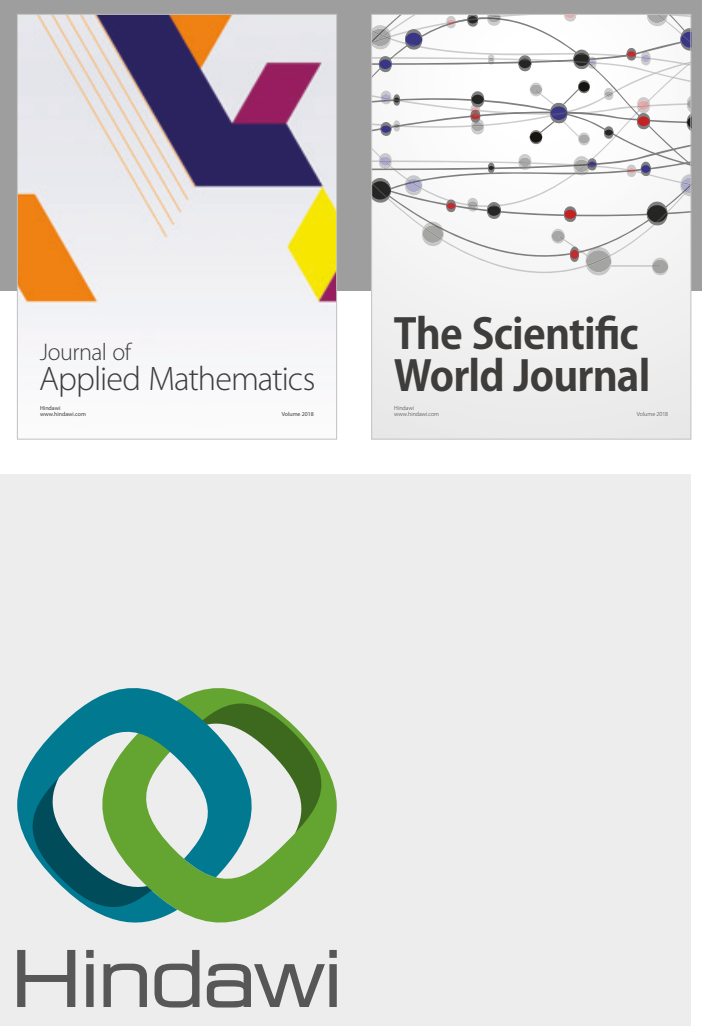

Submit your manuscripts at

www.hindawi.com

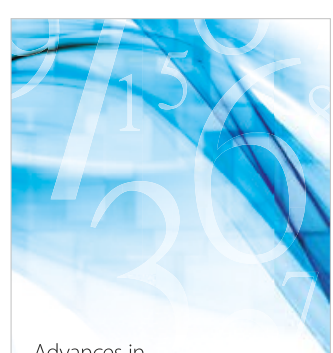

Advances in
Numerical Analysis
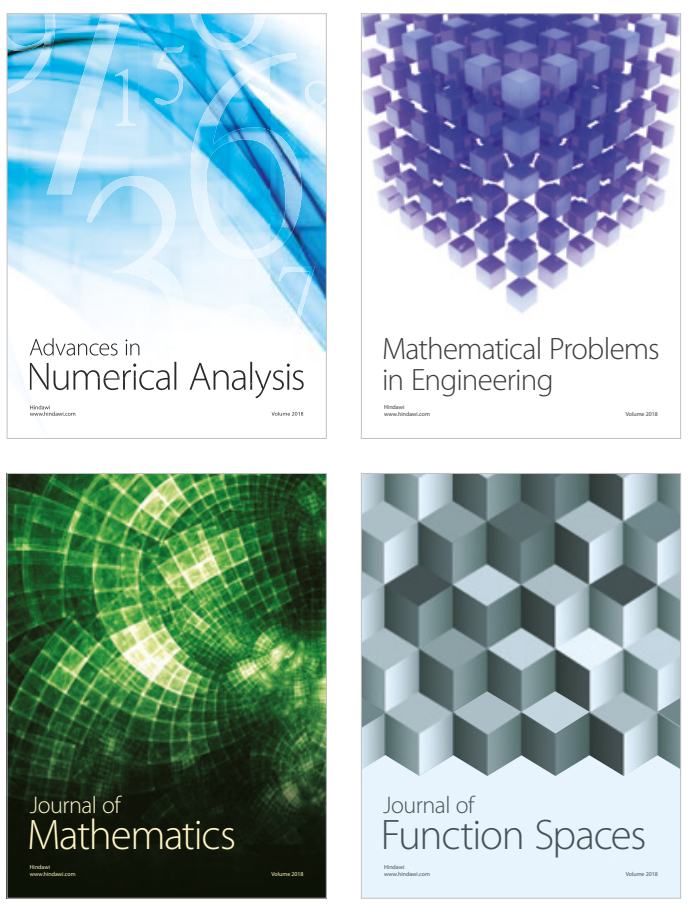

Mathematical Problems in Engineering

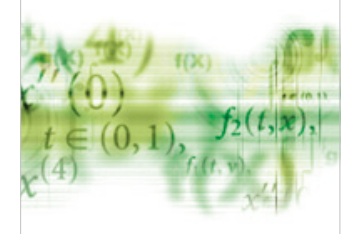

International Journal of

Differential Equations

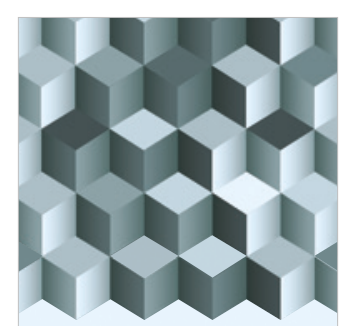

Journal of

Function Spaces

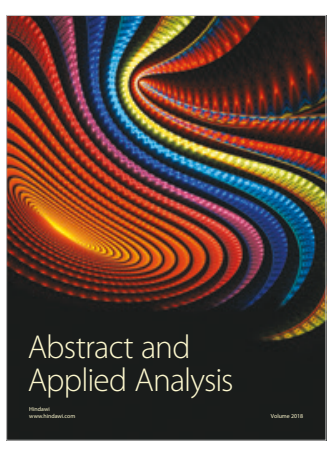

The Scientific

World Journal

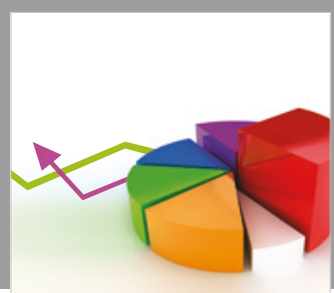

Journal of

Probability and Statistics
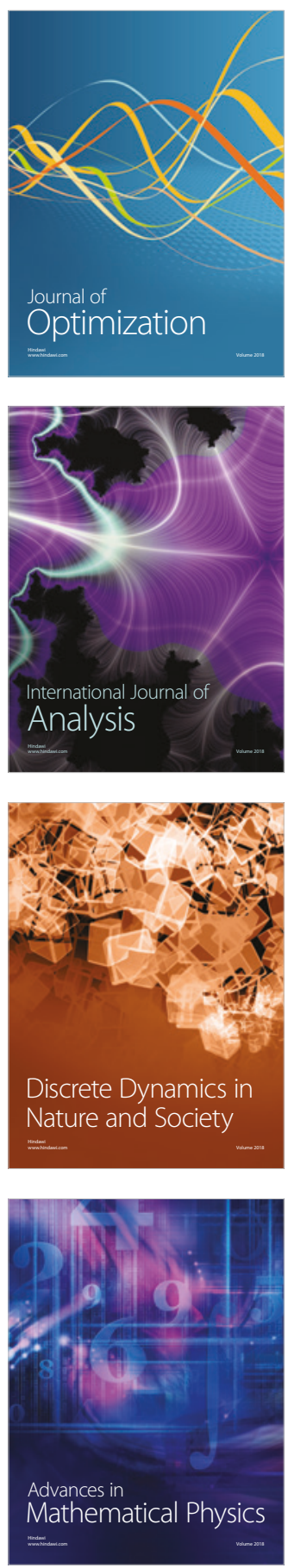